\title{
Knowledge, awareness and practices of malaria in Western Area Rural District, Sierra Leone: a household-based cross-sectional survey in the middle of National Malaria Strategic Plan (2016-2020)
}

Lili WANG

Chinese Center for Disease Control and Prevention https://orcid.org/0000-0003-3000-1090

Jianhai Yin ( $\square$ yinjh@nipd.chinacdc.cn)

Canjun Zheng

Chinese Center for Disesase Control and Prevention

Samuel Juana Smith

Ministry of Health and Sanitation

Esther Ngegba

Chinese Center for Disease Control and Prevention

Xiaoxia Huang

National Institute for Viral Disease Control and Prevention, Chinese Center for Disease Control and Prevention

Anitta Kamara

Ministry of Health and Sanitation

Xia Chen

National Institute for Communicable Disease Control and Prevention

Xu Wang

National Institute of Parasitc Disease, Chinese Center for Disease Control and Prevention

Wei Luo

National Center for AIDS/STD Control and PRevention, Chinese Center for Disease Control and Prevention

Biao Kan

National Institute for Communicable Disease Control and Prevention, Chinese Center for Disease Control and PRevention

\section{Research}

Keywords: malaria, sierra leone, NMSP, grafton, jui, kossoh, western area rural district

Posted Date: August 31st, 2020

DOI: https://doi.org/10.21203/rs.3.rs-16373/v2

License: (c) (1) This work is licensed under a Creative Commons Attribution 4.0 International License. Read Full License 


\section{Abstract}

Background The malaria epidemic is high in Sierra Leone, and the implementation of the National Malaria Strategic Plan (2016-2020) has reached its middle stage. In order to guide the interventions more specifically in future, a household-based cross-sectional survey was conducted to understand the public perception of knowledge, attitudes and practices of malaria and its control.

Methods Three communities (Grafton, Jui and Kossoh) in Western Area Rural District within close proximity to Sierra Leone's capital city of Freetown were included. Households were randomly selected and interviewed with a structural questionnaire covering malaria infection, diagnosis, treatment and prevention, as well as the knowledge of malaria prevention, in collaboration with the National Malaria Control Program of the Ministry of Health and Sanitation, Sierra Leone.

Results A total of 262 qualified questionnaires were included. The average cost for meals per day is around 30000 Leones in each household. The awareness rate of having heard of malaria is $98.1 \%$ (257/262) and knowing mosquito biting as its main route of transmission is $86.6 \%(227 / 262)$ respectively. And $80.9 \%$ $(212 / 262)$ of the respondents sought health advice or treatment for the illness, and similar percentage of them could be tested for malaria, mostly through RDTs. A great demand of long-lasting insecticidal nets (72.1\%) was raised to fulfill the high shortage $(61.8 \%, 162 / 262)$ in households, and of them there were 66 families having children under five years old.

Conclusion Malaria burden is still high. Although public awareness of malaria prevention sounds well in this survey, the fact that the coverage of supplies and the use of preventive measures against malaria is low in households within the three communities. It is suggested that an advanced campaign should be carried out to scale up not only the knowledge on malaria but also the actual coverage and usage of malaria prevention measures, contributing to the achievements of planned objectives.

\section{Background}

Malaria is endemic in Sierra Leone; the entire population of this country are exposed and live in stable malarial areas [1]. Sierra Leone's high malaria disease burden, accounted for approximately $48 \%$ of outpatient morbidity and around $38 \%$ of mortality among children under five according to the national Malaria Indicator Survey (2016) [2]. Although significant progress on reducing mortality has been made in the fight against malaria, it is still a major public health concern. Malaria control remains a priority within the national health agenda in this country [3].

A multi-pronged strategy for malaria control, including vector control interventions, diagnostic testing, treatment with quality-assured artemisin-based combination therapies, and standardized case management training manuals for community and facility treatment providers have been developed and implemented in Sierra Leone corresponding to WHO recommendations [3]. And, it was expected to achieve: $1.80 \%$ of the population at least have appropriate knowledge and up-take/practice of malaria prevention and management services, 2. all the population at risk will be protected with appropriate preventive interventions, and $3.80 \%$ of suspected malaria cases at least have access to confirmatory diagnosis and all malaria cases receive effective treatment by 2018, according to the current Sierra Leone National Malaria Strategic Plan (2016-2020) (SL-NMSP) [3].

The awareness of malaria symptoms, transmission, prevention and treatments is closely related to the implementation of malaria control programs [4-6]. A malaria knowledge, attitudes and practices (KAP) survey could help policy makers to better understand current situation and guide practices in fighting against malaria. Therefore, this study is conducted to understand the public perception of knowledge, attitudes and practices of malaria and its control measures through the household-based survey in the middle of implementation of SL-NMSP.

\section{Materials And Methods}

\section{Study site}

Three communities (Grafton, Jui and Kossoh) in Western Area Rural District within close proximity to Sierra Leone's capital city Freetown were included in this household-based survey on malaria. This district is home to a very religiously and ethnically diverse population. Grafton is a trade center. Jui and Kossoh are neighborhood towns. Kossoh town seat around a large forest reserve, its major industries are farming and coal mining.

\section{Participants, questionnaire and data collection}

A total of 300 households in the designated communities were selected randomly using a cluster sampling design as survey respondents in the three communities. One adult member from selected households were interviewed with a structured questionnaire covering demographic information, economic status, basic knowledge of malaria as well as the practice of malaria prevention and control in families. When asked about the medicine being used, a package of various drugs was displayed to participants.

The survey was conducted in December 2018 with collaboration of the National Malaria Control Program of the Ministry of Health and Sanitation, Sierra Leone. Local staff from Sierra Leone-China Friendship Biological Safety Laboratory [7] were trained in prior and conducted the survey.

\section{Data management and statistical analysis}

Data was input and cross-checked by EpiData version 3.1 [8, 9]. Then, descriptive data and percentages were presented using Microsoft Excel 2010 software. Differences in distribution according to the daily cost for meals in each household were evaluated using the chi-square $\left(\chi^{2}\right)$ test or Fisher's exact test by SPS software version 20.0 (IBM, USA) and $P<0.05$ was considered statistically significant. 


\section{Results}

A total of 300 households were investigated, and 262 qualified questionnaires were finally included into the following analysis after data checking of completeness of the questionnaire and logical accuracy before and after. It covered 1645 residents, and about 6 persons were in per family. And the average cost for meals per day is around 30000 Leones in each household (One US dollor was equal to 8000 Leones around during December 2018). Three groups were set up according to the meal cost level. Group 1 was $\leq 20000$ Leones/household per day, there were 475 persons in 97 households; Group 2 was $\leq$ 40000 Leones/household per day, 778 persons were in 123 households; and a sum of 392 persons from 42 households were in Group 3 at the meal cost > 40000 Leones/household per day.

\section{Malaria infection, diagnosis and treatment}

A total of 308 persons in 87 households, 430 persons in 106 households and 191 persons in 39 households from Group 1 - 3 respectively were reported to have fever in the year of 2018 ( $P=0.594$, Fisher's exact test). The frequency and the population of malaria suffering among them in the year of 2018 was shown in Table 1.

Moreover, there were about $79.4 \%, 79.7 \%$ and $88.1 \%$ of the respondents from group $1-3$ accordingly seeking health advice or treatment for the illness from any source ( $P=0.421$, Fisher's exact test). And, $76.6 \%, 71.4 \%$ and $64.9 \%$ of the respondents among three groups reported to prefer public medical sectors only respectively ( $P=0.117$, Fisher's exact test) (Table 2). In addition, no significance was found related to the selection of different medical sectors among three groups referring to public sectors $(P=0.765$, Fisher's exact test) and private sectors $(P=0.468$, Fisher's exact test) separately (Table 3$)$.

Furthermore, $84.5 \%, 84.6 \%$ and $83.3 \%$ of the respondents from Group $1-3$ respectively reported that they and their family members always went to see a health worker or doctor when they were suspected to be infected with malaria ( $P=0.487$, Fisher's exact test). Of those went to see a health worker or doctor, they went every time or most of times when being suspected as malaria and the overall frequency was similar among the three groups $\left(\chi^{2}=2.882, d f=6, P=\right.$ 0.830) (Table 4).

In their memory, the health worker or doctor performed a malaria test when they visited due to the suspected malaria $(80.1 \%)(P=0.435$, Fisher's exact test), and malaria RDT was the most used test $\left(P=0.882\right.$, Fisher's exact test), but nearly half of the doctors or health workers didn't explain the test for them $\left(\chi^{2}=\right.$ 2.783, $d f=6, P=0.841$ ) (Table 4).

Most of respondents reported taking anti-malarial medicine every time when being diagnosed as malaria or most of the time ( $P=0.344$, Fisher's exact test), and about $79.8 \%$ of them took the full dosages every time prescribed by doctor/health worker $(P=0.489$, Fisher's exact test), and Artesunate+Lumafantrine $(51.7 \%)$ and Artesunate+Amodiaquine (19.1\%) were the first two choices. The reason of not taking all medicine was mainly that they recovered before finishing all the dosages ( $P=0.815$, Fisher's exact test). Moreover, about $80.2 \%$ of the respondents reported to start taking the anti-malarial medicine since the same day when they were fever $(P=0.095$, Fisher's exact test), and about $64.5 \%$ of them responded that all kinds of the anti-malarial medicine were not free $(P$ $=0.399$, Fisher's exact test) (Table 4).

\section{Malaria prevention measures}

In this survey, 188 households had long-lasting insecticidal nets (LLINs) $\left(\chi^{2}=1.466, d f=2, P=0.482\right)$, but more nets were required because 189 respondents said that they didn't have enough LLINs in their households $(P=0.253$, Fisher's exact test), so resulting in children under 5 years in 66 households couldn't sleep under LLINs $(P=0.410$, Fisher's exact test). And only 146 respondents slept under nets at the night before the survey $(P=0.331$, Fisher's exact test). To make matters worse, some members in 162 households didn't sleep under LLINs which would cause cross-infection $\left(\chi^{2}=4.359, d f=4, P=0.363\right)$. The LLINs were mainly distributed by the governmental hospital/health centers and community health centers (Table 5).

Besides, a total of 143 households never sprayed insecticide indoor to kill mosquitoes $(P=0.217$, Fisher's exact test), and 225 households never sprayed insecticide outside ( $P=0.003$, Fisher's exact test), especially among group $1(89.7 \%)$ and group $2(89.4 \%)$. Furthermore, more than three quarters of the respondents reported that they didn't have doors or windows screen for preventing mosquitoes enter into their houses $(P=0.020$, Fisher's exact test), especially in the first group (85.6\%). Additionally, most families reported staying outside of the house at night $(P=0.800$, Fisher's exact test) (Table 5).

\section{Knowledge of malaria}

In this survey, almost all respondents have heard about malaria $(98.1 \%, 257 / 262)$ and its main transmission pattern of mosquito bites (86.6\%, 227/262). Fever, body ache or joint pain, and loss of appetite were the top three clinical manifestations they reported (Table 6). A total of 173 respondents reported that they would always go to see the doctor/health worker when they were suspected as malaria, and 48 interviewees would take some anti-malarial medicine kept in house firstly. Expensive costs (mentioned by 176 respondents) and the far distance (mentioned by 26 respondents) were the main factors that stop people seeing the doctor/health worker (Table 6). Sleeping under LLINs (198), keeping surrounding clean (84) and using mosquito insecticide spray (20) were the most selected choices for the malaria prevention (Table 6).

\section{Discussion}

Malaria remains one of the most serious public health issues responsible for morbidity and mortality in Sierra Leone, although overall high levels of knowledge on the causes of malaria, prevention mechanisms, symptoms, and health care seeking to treat malaria were found among Sierra Leoneans in the present study which is in favor of malaria control [10-12] just like that in the MIS 2013 \& $2016[2,13]$. 
Vector control through the use of LLINs and indoor residual spraying (IRS) interventions are the most commonly used tools globally to reduce malaria transmission through preventing human-vector contact and kill the vector mosquitoes $[14,15]$. And it was expected to cover all population at risk with preventive measures including the use of LLINs, IRS and larval source management by 2017 in Sierra Leone. However, $72.1 \%$ of respondents requiring more nets, may be the potential reason of the high percentage $(61.8 \%, 162 / 262)$ of households and children under five years old in 66 families couldn't sleep under the nets at night in this survey. This indicates a big gap in obtaining and using nets by the most vulnerable groups who are not benefiting as much as hoped from malaria interventions. Besides, screen for doors and windows which is cost-effective to install and maintain has been considered as a supplementary public health intervention to prevent human bitten by the mosquito vectors indoors and significantly reduce malaria transmission. However, it was easily ignored in common malaria control campaigns $[16,17]$, such as less than $25 \%$ of households had door or window screen in this survey, in addition to a low level of awareness of the role of screen. In addition, the low usage of IRS and outside spraying plus the high engagement in activities outside of the house at night was found, although there were so many mosquitoes.

Early diagnosis and prompt treatment of malaria reduces transmission of the disease and prevents deaths. It is critical that people seek diagnosis and care as soon as they experience any symptoms of malaria. It is nice to see that more than $80 \%$ of the respondents could go to the doctor in time, and similar percentage of them could be tested for malaria, and malaria RDTs was used mostly. But around three quarters of respondents said that the doctors didn't interpret test results to patients. Thereby, a good opportunity for health education and promotion on malaria control and prevention may be missed. And a home-based rapid diagnostic test by trained family members rather than visiting a healthcare facility for clinical testing may improve the timeliness of malaria diagnosis $[18,19]$. Moreover, complete adherence of taking antimalarial medicine approached to $80 \%$, while similar ratio of self-administration at home. Explanations included sickness after the first dose, insufficient food to take the medicine, forgetting to take the medicine, and poor instructions provided by the $\mathrm{CHC}[20]$. In addition, the cost of medical treatment and the distance from the hospital must also be considered.

\section{Conclusion}

In conclusion, the public awareness of malaria prevention was relatively satisfactory in this survey, but the malaria burden is still higher than expected due to the fact that the coverage of anti-malarial supplies and the use of preventive measures against malaria is low in households within the three communities. Thus, an advanced campaign should be carried out to scale up not only the knowledge on malaria but also the actual coverage and use rate of malaria prevention measures, thereby achieve the goal of reducing new cases of the disease by 40 percent by 2020 in Sierra Leone.

\section{Declarations}

\section{Acknowledgement}

We appreciate the Sierra Leonean staff for their wonderful work in the Sierra Leone-China Friendship Biological Safety Laboratory.

\section{Contribution}

JHY and CJZ conceived the study, developed questionnaire, conducted fieldwork. LLW and JHY analyzed data, and wrote the manuscript. SJS and BK contributed to the study design. EN and AK conducted fieldwork and supervised fieldwork. XXW, XC, XW and WL contributed to data collation and crosschecking. All authors read and approved the final draft.

\section{Conflict of interest}

No conflicts of interest were reported.

\section{Financial support}

This study was supported by Sierra Leone-China Second Phase of the Fixed Biological Safety Laboratory Technical Cooperation Project.

\section{Ethics Approval and consent to participate}

This survey was approved by the Sierra Leone Ethics and Scientific Review Committee. The purpose and procedure of the study were explained to the participants prior to obtaining their consent.

\section{Consent for Publication}

Not applicable.

\section{Availability of Data and Materials}

The datasets used and/or analyzed during the current study are available from the corresponding author on reasonable request.

\section{References}

1. World Health Organization. World Malaria Report 2018. Geneva: World Health Organization, 2018.

2. National Malaria Control Programme (NMCP) [Sierra Leone], Statistics Sierra Leone, University of Sierra Leone, Catholic Relief Services, and ICF. Sierra Leone Malaria Indicator Survey. Freetown, Sierra Leone: NMCP, SSL, CRS, and ICF, 2016. 
3. National Malaria Control Programme: Sierra Leone Malaria Control Strategic Plan (2016-2020). 2015.

4. Phyo Aung Naing, Thae Maung Maung, Jaya Prasad Tripathy, Tin Oo, Khin Thet Wai, Aung Thi. Awareness of malaria and treatment-seeking behaviour among persons with acute undifferentiated fever in the endemicregions of Myanmar. Tropical Medicine and Health, 2017, 45:31.

5. Mary M. Mathania, Sharadhuli I. Kimera1 and Richard S. Silayo. Knowledge and awareness of malaria and mosquito biting behaviour in selected sites within Morogoro and Dodoma regions Tanzania. Malar J, 2016, 15:287.

6. Alelign A, Petros B. Knowledge, attitudes and practices of malaria transmission and preventive measures in Woreta town, Northwest Ethiopia. BMC Res Notes, 2018, 11:491.

7. Lili Wang, Xiaochun Wang, Mingfan Pang, Xiuqiong Hu, Xiaopeng Qi, Xiaoping Dong. The Practice of the Public Health Cooperation in the Republic of Sierra Leone: Contributions and Experiences. China CDC Weekly, 2020, 2(2): 28-31.

8. Lauritsen JM, Bruus M. EpiData (version 3). A comprehensive tool for validated entry and documentation of data. The EpiData Association, Odense, Denmark, 2003-2008.

9. Lauritsen JM, Bruus M, Myatt MA. EpiData (version 1.0-1.5). A tool for validated entry and documentation of data. County of Funen Denmark and Brixton Health UK. 2001.

10. Yasuoka J, Kikuchi K, Nanishi K, Ly P, Thavrin B, Omatsu T, Mizutani T. Malaria knowledge, preventive actions, and treatment-seeking behavior among ethnic minorities in Ratanakiri Province, Cambodia: a community-based cross-sectional survey. BMC Public Health, 2018, 18:1206.

11. Balami AD, Said SM, Zulkefli NAM, Norsa'adah B, Audu B. Knowledge, motivation, self-efficacy, and their association with insecticidal net use among pregnant women in a secondary health centre in Maiduguri, Nigeria. Malar J, 2018, 17:359.

12. Moscibrodzki P, Dobelle M, Stone J, Kalumuna C, Chiu YM, Hennig N. Free versus purchased mosquito net ownership and use in Budondo sub-county, Uganda. Malar J, 2018, 17:363.

13. National Malaria Control Programme (NMCP) [Sierra Leone], Statistics Sierra Leone, University of Sierra Leone, Catholic Relief Services, and ICF International. Sierra Leone Malaria Indicator Survey. Freetown, Sierra Leone: NMCP, SSL, CRS, and ICF International, 2013.

14. Bhatt S, Weiss DJ, Cameron E, Bisanzio D, Mappin B, Dalrymple U, Battle K, Moyes CL, Henry A, Eckhoff PA, et al. The effect of malaria control on Plasmodium falciparum in Africa between 2000 and 2015. Nature, 2015, 526:207-211.

15. Killeen GF, Smith TA, Ferguson HM, Mshinda H, Abdulla S, Lengeler C, Kachur SP. Preventing childhood malaria in Africa by protecting adults from mosquitoes with insecticide-treated nets. PLoS Med, 2007, 4:e229.

16. Kirby MJ, Ameh D, Bottomley C, Green C, Jawara M, Milligan PJ, Snell PC, Conway DJ, Lindsay SW. Effect of two different house screening interventions on exposure to malaria vectors and on anaemia in children in The Gambia: a randomised controlled trial. Lancet, 2009, 374:998-1009.

17. Killeen GF, Masalu JP, Chinula D, Fotakis EA, Kavishe DR, Malone D, Okumu F. Control of Malaria Vector Mosquitoes by Insecticide-Treated Combinations of Window Screens and Eave Baffles. Emerg Infect Dis, 2017, 23:782-789.

18. Elmardi KA, Malik EM, Abdelgadir T, Ali SH, Elsyed AH, Mudather MA, Elhassan AH, Adam I. Feasibility and acceptability of home-based management of malaria strategy adapted to Sudan's conditions using artemisinin-based combination therapy and rapid diagnostic test. Malar J, $2009,8: 39$.

19. Thiam S, Thwing J, Diallo I, Fall FB, Diouf MB, Perry R, Ndiop M, Diouf ML, Cisse MM, Diaw MM, Thior M. Scale-up of home-based management of malaria based on rapid diagnostic tests and artemisinin-based combination therapy in a resource-poor country: results in Senegal. Malar J, 2012, 11:334.

20. Gerstl S, Dunkley S, Mukhtar A, Baker S, Maikere J. Successful introduction of artesunate combination therapy is not enough to fight malaria: results from an adherence study in Sierra Leone. Trans R Soc Trop Med Hyg, 2010, 104(5):328-35.

\section{Tables}

Table 1. The distribution of malaria cases in households

\begin{tabular}{lllll}
\hline Group & \multicolumn{4}{l}{ Number of respondents suffered from } \\
\cline { 2 - 5 } & Once & Twice & 3 times & $>3$ times \\
\hline 1 & $46 / 20$ & $62 / 29$ & $29 / 12$ & $107 / 38$ \\
2 & $68 / 32$ & $52 / 24$ & $31 / 13$ & $133 / 43$ \\
3 & $15 / 12$ & $32 / 13$ & $1 / 1$ & $35 / 10$ \\
\hline
\end{tabular}

Table 2. The distribution of medical sectors people seeking health advice or treatment

\begin{tabular}{ccccc}
\hline Medical sector & \multicolumn{3}{c}{ Group } & Total \\
\cline { 2 - 4 } & 1 & 2 & 3 & \\
\hline Public sector only & 59 & 70 & 24 & 153 \\
Private medical sector only & 14 & 17 & 12 & 43 \\
Both sectors & 3 & 11 & 1 & 15 \\
Don't answer & 1 & 0 & 0 & 1 \\
\hline Total & 77 & 98 & 37 & 212 \\
\hline
\end{tabular}

Table 3. The detail of public or private medical sectors people selected for health care seeking 


\begin{tabular}{|c|c|c|c|c|c|c|c|c|c|c|c|}
\hline \multirow[t]{2}{*}{ Group } & \multicolumn{6}{|c|}{ Public medical sectors } & \multicolumn{5}{|c|}{ Private medical sectors } \\
\hline & $\begin{array}{l}\text { Government } \\
\text { Hospital }\end{array}$ & $\begin{array}{l}\text { Government } \\
\text { Health } \\
\text { Center }\end{array}$ & $\begin{array}{l}\text { Mobile } \\
\text { Clinic }\end{array}$ & $\begin{array}{l}\text { Community } \\
\text { health } \\
\text { worker }\end{array}$ & $\begin{array}{l}\text { Other } \\
\text { Public } \\
\text { Sector }\end{array}$ & Subtotal & $\begin{array}{l}\text { Private } \\
\text { Hospital }\end{array}$ & $\begin{array}{l}\text { Private } \\
\text { Clinic }\end{array}$ & $\begin{array}{l}\text { Mission/Faith- } \\
\text { based } \\
\text { Hospital }\end{array}$ & $\begin{array}{l}\text { Mission/Faith- } \\
\text { based Clinic }\end{array}$ & Pharmi \\
\hline 1 & 42 & 9 & 5 & 0 & 3 & 59 & 7 & 0 & 0 & 1 & 2 \\
\hline 2 & 44 & 13 & 6 & 4 & 3 & 70 & 9 & 1 & 1 & 1 & 4 \\
\hline 3 & 17 & 4 & 2 & 1 & 0 & 24 & $6 *$ & 0 & 0 & $4^{*}$ & 2 \\
\hline
\end{tabular}

*: there was one respondent seeking advice or treatment in private sectors of private hospital and Mission/Faith-based Clinic.

Table 4. Malaria diagnosis and anti-malarial medicine taking 
эn you and your family suspected you were infected with malaria, did you always go to see a health worker/doctor?

\begin{tabular}{|c|c|c|c|c|c|}
\hline & 82 & 104 & 35 & 221 & $84.4 \%$ \\
\hline & 10 & 8 & 2 & 20 & $7.6 \%$ \\
\hline answer & 5 & 11 & 5 & 21 & $8.0 \%$ \\
\hline \multicolumn{6}{|l|}{ How often? } \\
\hline $\mathrm{y}$ time & 38 & 42 & 16 & 96 & $43.4 \%$ \\
\hline t of time & 26 & 44 & 13 & 83 & $37.6 \%$ \\
\hline lom & 11 & 12 & 3 & 26 & $11.8 \%$ \\
\hline$r$ when they showed severe condition & 7 & 6 & 3 & 16 & $7.2 \%$ \\
\hline
\end{tabular}

in you or any member of your family suspected that they had malaria, did the health worker/ doctor conduct a malaria test?

\begin{tabular}{|c|c|c|c|c|c|}
\hline & 76 & 98 & 36 & 210 & $80.2 \%$ \\
\hline & 15 & 14 & 2 & 31 & $11.8 \%$ \\
\hline answer & 6 & 11 & 4 & 21 & $8.0 \%$ \\
\hline \multicolumn{6}{|l|}{ the Doctor / health worker explain to you the test to be done? } \\
\hline & 53 & 69 & 22 & 144 & $55.0 \%$ \\
\hline & 25 & 24 & 8 & 57 & $21.8 \%$ \\
\hline remember & 9 & 15 & 7 & 31 & $11.8 \%$ \\
\hline answer & 10 & 15 & 5 & 30 & $11.5 \%$ \\
\hline \multicolumn{6}{|l|}{ at type of test did they say they were going to perform? } \\
\hline & 51 & 66 & 26 & 143 & $54.6 \%$ \\
\hline scopy & 1 & 3 & 1 & 5 & $1.9 \%$ \\
\hline remember & 30 & 37 & 9 & 76 & $29.0 \%$ \\
\hline answer & 15 & 17 & 6 & 38 & $14.5 \%$ \\
\hline \multicolumn{6}{|c|}{ ən you and your family were infected with malaria, did you take the anti-malarial medicine? } \\
\hline time & 49 & 40 & 19 & 108 & $41.2 \%$ \\
\hline of time & 30 & 49 & 15 & 94 & $35.9 \%$ \\
\hline \multirow[t]{2}{*}{$\mathrm{n}$} & 9 & 15 & 2 & 26 & $9.9 \%$ \\
\hline & 0 & 2 & 0 & 2 & $0.8 \%$ \\
\hline vhen they showed severe condition & 5 & 7 & 3 & 15 & $5.7 \%$ \\
\hline answer & 4 & 10 & 3 & 17 & $6.5 \%$ \\
\hline \multicolumn{6}{|l|}{ at anti-malarial medicines did you take? } \\
\hline nsidar & 3 & 3 & 0 & 6 & $2.3 \%$ \\
\hline ination with Artemisinin & 1 & 2 & 0 & 3 & $1.1 \%$ \\
\hline inate+Lumafantrine & 58 & 69 & 24 & 151 & $57.6 \%$ \\
\hline Inate+Amodiaquine & 17 & 28 & 9 & 54 & $20.6 \%$ \\
\hline aquine & 4 & 4 & 1 & 9 & $3.4 \%$ \\
\hline $1 \mathrm{e}$ & 0 & 1 & 1 & 2 & $0.8 \%$ \\
\hline s: specify & 16 & 18 & 5 & 39 & $14.9 \%$ \\
\hline answer & 7 & 8 & 3 & 18 & $6.9 \%$ \\
\hline \multicolumn{6}{|l|}{ эn did (NAME(S)) take the anti-malarial medicine? } \\
\hline day after fever & 87 & 91 & 32 & 210 & $80.2 \%$ \\
\hline lay after fever & 4 & 15 & 5 & 24 & $9.2 \%$ \\
\hline ay after fever & 0 & 0 & 0 & 0 & $0.0 \%$ \\
\hline or more day after fever & 1 & 7 & 1 & 9 & $3.4 \%$ \\
\hline know & 0 & 2 & 0 & 2 & $0.8 \%$ \\
\hline answer & 5 & 8 & 4 & 17 & $6.5 \%$ \\
\hline \multicolumn{6}{|l|}{ the antimalarial drugs FREE which you and your family took? } \\
\hline ley are free for all & 29 & 33 & 8 & 70 & $26.7 \%$ \\
\hline \multirow[t]{2}{*}{ ly for children, pregnant women and breast-feeding women } & 1 & 6 & 2 & 9 & \\
\hline & & & & & $3.4 \%$ \\
\hline is FREE & 64 & 76 & 29 & 169 & $64.5 \%$ \\
\hline answer & 3 & 8 & 3 & 14 & $5.3 \%$ \\
\hline
\end{tabular}

эn you and your family were infected with malaria, did you take the full dosage of antimalarial drugs which was prescribed by doctor/health worker?

\begin{tabular}{|c|c|c|c|c|c|}
\hline ake full dosages every time & 78 & 96 & 35 & 209 & $79.8 \%$ \\
\hline metimes some dosage was left & 15 & 15 & 3 & 33 & $12.6 \%$ \\
\hline me dosages were left every time & 1 & 3 & 0 & 4 & $1.5 \%$ \\
\hline answer & 3 & 9 & 4 & 16 & $6.1 \%$ \\
\hline \multicolumn{6}{|l|}{ If not all drugs taken, please explain why: } \\
\hline got recovery before finishing all of them & 15 & 15 & 3 & 33 & $89.2 \%$ \\
\hline drugs made me have headache, nausea & 0 & 0 & 0 & 0 & $0.0 \%$ \\
\hline I too busy to remember taking all the dosage & 0 & 2 & 0 & 2 & $5.4 \%$ \\
\hline כrs: specify & 1 & 1 & 0 & 2 & $5.4 \%$ \\
\hline 't answer & 0 & 0 & 0 & 0 & $0.0 \%$ \\
\hline
\end{tabular}

Table 5. Malaria prevention practices in the communities 


\begin{tabular}{|c|c|c|c|c|c|}
\hline \multirow[t]{2}{*}{ Question \& Answer } & \multicolumn{3}{|c|}{ Group } & \multirow[t]{2}{*}{ Total } & \multirow[t]{2}{*}{ Percentage } \\
\hline & 1 & 2 & 3 & & \\
\hline \multicolumn{6}{|c|}{ 1. Do you have a mosquito treated bed nets in your home? } \\
\hline Yes & 70 & 91 & 27 & 188 & $71.8 \%$ \\
\hline No & 27 & 32 & 15 & 74 & $28.2 \%$ \\
\hline \multicolumn{6}{|c|}{ 2. Did you sleep under a mosquito net last night? } \\
\hline Yes & 57 & 71 & 18 & 146 & $55.7 \%$ \\
\hline No & 37 & 46 & 23 & 106 & $40.5 \%$ \\
\hline Don't answer & 3 & 6 & 1 & 10 & $3.8 \%$ \\
\hline \multicolumn{6}{|c|}{ 3. Is there anyone in your household who did not sleep under treated bed nets last night? } \\
\hline Yes & 53 & 81 & 28 & 162 & $61.8 \%$ \\
\hline No & 37 & 34 & 13 & 84 & $32.1 \%$ \\
\hline Don't answer & 7 & 8 & 1 & 16 & $6.1 \%$ \\
\hline \multicolumn{6}{|c|}{ 4. Are there enough treated bed nets in your household? } \\
\hline Yes & 31 & 25 & 9 & 65 & $24.8 \%$ \\
\hline No & 62 & 95 & 32 & 189 & $72.1 \%$ \\
\hline Don't answer & 4 & 3 & 1 & 8 & $3.1 \%$ \\
\hline \multicolumn{6}{|c|}{ 5. Do all children under 5 years in your household sleep under treated bed nets at night? } \\
\hline Yes & 36 & 52 & 14 & 102 & $38.9 \%$ \\
\hline No & 25 & 28 & 13 & 66 & $25.2 \%$ \\
\hline No children under 5 & 36 & 41 & 13 & 90 & $34.4 \%$ \\
\hline Don't answer & 0 & 2 & 2 & 4 & $1.5 \%$ \\
\hline \multicolumn{6}{|l|}{ 6. Where did you get the treated bed nets? } \\
\hline \multirow[t]{2}{*}{ Government Hospital/Health Center } & 56 & 57 & 17 & & \\
\hline & & & & 130 & $49.6 \%$ \\
\hline Mobile Clinic & 1 & 0 & 0 & 1 & $0.4 \%$ \\
\hline \multirow[t]{2}{*}{ Community Health Center } & 8 & 23 & 9 & & \\
\hline & & & & 40 & $15.3 \%$ \\
\hline Private Hospital/ Clinic & 0 & 7 & 1 & 8 & $3.1 \%$ \\
\hline Pharmacy & 1 & 0 & 0 & 1 & $0.4 \%$ \\
\hline Shop & 2 & 5 & 3 & 10 & $3.8 \%$ \\
\hline Traditional Healer & 0 & 0 & 0 & 0 & $0.0 \%$ \\
\hline Others & 13 & 12 & 1 & 26 & $9.9 \%$ \\
\hline Don't answer & 16 & 24 & 13 & 53 & $20.2 \%$ \\
\hline \multicolumn{6}{|c|}{ 7. Did you spray insecticide to kill mosquitoes in your house? } \\
\hline Often & 13 & 13 & 7 & 33 & $12.6 \%$ \\
\hline Sometimes & 9 & 20 & 8 & 37 & $14.1 \%$ \\
\hline Seldom & 13 & 27 & 8 & 48 & $18.3 \%$ \\
\hline Never & 61 & 63 & 19 & 143 & $54.6 \%$ \\
\hline Don't answer & 1 & 0 & 0 & 1 & $0.4 \%$ \\
\hline \multicolumn{6}{|c|}{ 8. Did you spray insecticide to kill mosquitoes outside your house? } \\
\hline Often & 0 & 4 & 1 & 5 & $1.9 \%$ \\
\hline Sometimes & 3 & 1 & 2 & 6 & $2.3 \%$ \\
\hline Seldom & 6 & 6 & 8 & 20 & $7.6 \%$ \\
\hline Never & 87 & 110 & 28 & 225 & $85.9 \%$ \\
\hline Don't answer & 1 & 2 & 3 & 6 & $2.3 \%$ \\
\hline \multicolumn{6}{|c|}{ 9. Does your house have doors or windows screen which could stop the mosquitoes to go into the house? } \\
\hline Yes & 13 & 34 & 11 & 58 & $22.1 \%$ \\
\hline No & 83 & 89 & 30 & 202 & $77.1 \%$ \\
\hline Don't answer & 1 & 0 & 1 & 2 & $0.8 \%$ \\
\hline \multicolumn{6}{|c|}{ 10. Do you and your family often stay outside of the house at night (such as for walk, exercises, enjoy the cool air, work, etc) } \\
\hline Often & 68 & 85 & 31 & 184 & $70.2 \%$ \\
\hline Sometimes & 19 & 26 & 6 & 51 & $19.5 \%$ \\
\hline Seldom & 5 & 8 & 2 & 15 & $5.7 \%$ \\
\hline Never & 4 & 2 & 3 & 9 & $3.4 \%$ \\
\hline Don't answer & 1 & 2 & 0 & 3 & $1.1 \%$ \\
\hline
\end{tabular}

Table 6. Knowledge of malaria transmission, symptom and prevention 


\begin{tabular}{|c|c|c|c|c|c|}
\hline \multirow[t]{2}{*}{ Question \& Answer } & \multicolumn{3}{|c|}{ Group } & \multirow[t]{2}{*}{ Total } & \multirow[t]{2}{*}{ Percentage } \\
\hline & 1 & 2 & 3 & & \\
\hline \multicolumn{6}{|c|}{ 1. Have you or any member of your family ever heard of an illness called malaria? } \\
\hline Yes & 94 & 121 & 42 & 257 & $98.1 \%$ \\
\hline No & 3 & 2 & 0 & 5 & $1.9 \%$ \\
\hline \multicolumn{6}{|l|}{ 2. In your opinion, what cause malaria?* } \\
\hline Mosquito bites & 82 & 106 & 39 & 227 & $86.6 \%$ \\
\hline Eating immature sugarcane & 0 & 0 & 0 & 0 & $0.0 \%$ \\
\hline Eating dirty food & 3 & 3 & 1 & 7 & $2.7 \%$ \\
\hline Drinking beer/palm Wine & 0 & 0 & 0 & 0 & $0.0 \%$ \\
\hline Drinking dirty water & 7 & 8 & 1 & 16 & $6.1 \%$ \\
\hline Getting soaked with rain & 0 & 0 & 0 & 0 & $0.0 \%$ \\
\hline Cold or changing weather & 1 & 1 & 1 & 3 & $1.1 \%$ \\
\hline Witchcraft I. injections/drugs & 0 & 1 & 0 & 1 & $0.4 \%$ \\
\hline Eating oranges or mangos & 0 & 2 & 1 & 3 & $1.1 \%$ \\
\hline Eating plenty oil & 2 & 1 & 0 & 3 & $1.1 \%$ \\
\hline Sharing razors/blades & 0 & 0 & 0 & 0 & $0.0 \%$ \\
\hline Don't answer & 8 & 11 & 2 & 21 & $8.0 \%$ \\
\hline \multicolumn{6}{|l|}{ 3. Can you tell any symptoms of malaria?* } \\
\hline Fever & 39 & 59 & 18 & 116 & $44.3 \%$ \\
\hline Excessive sweating & 7 & 10 & 2 & 19 & $7.3 \%$ \\
\hline Feeling cold & 32 & 29 & 11 & 72 & $27.5 \%$ \\
\hline Headache & 24 & 27 & 4 & 55 & $21.0 \%$ \\
\hline Nausea and vomiting & 10 & 18 & 3 & 31 & $11.8 \%$ \\
\hline Dizziness & 21 & 29 & 16 & 66 & $25.2 \%$ \\
\hline Loss of appetite & 34 & 46 & 16 & 96 & $36.6 \%$ \\
\hline Body ache or joint pain & 43 & 45 & 14 & 102 & $38.9 \%$ \\
\hline Body weakness & 33 & 43 & 12 & 88 & $33.6 \%$ \\
\hline Refusing to eat or drink & 1 & 0 & 1 & 2 & $0.8 \%$ \\
\hline Jaundice & 5 & 1 & 0 & 6 & $2.3 \%$ \\
\hline Dark urine & 12 & 9 & 5 & 26 & $9.9 \%$ \\
\hline Others & 6 & 2 & 2 & 10 & $3.8 \%$ \\
\hline Don't answer & 1 & 0 & 0 & 1 & $0.4 \%$ \\
\hline \multicolumn{6}{|l|}{ 4. What should you do when you suspect getting malaria infection?* } \\
\hline Must go to see the doctor/health worker & 65 & 77 & 31 & 173 & $66.0 \%$ \\
\hline Take some anti-malarial drugs kept in house & 17 & 26 & 5 & 48 & $18.3 \%$ \\
\hline Not necessary to see the doctor/health worker and take drugs & 1 & 2 & 0 & 3 & $1.1 \%$ \\
\hline Go to see the doctor/health worker only when shown severe condition & 4 & 6 & 5 & 15 & $5.7 \%$ \\
\hline Others: Specify. & 6 & 9 & 3 & 18 & $6.9 \%$ \\
\hline Don't answer & 4 & 3 & 0 & 7 & $2.7 \%$ \\
\hline
\end{tabular}

5. What are the reasons you think that someone would not go to see the doctor/health worker when he or she gets malaria infection?*

$\begin{array}{lllll}\text { We are all used to it and no necessary to see the doctor } & 0 & 0 & 2 & 2\end{array}$

Prayers could make us recover

They are strong enough and could recover even if they do not see the doctor

$\begin{array}{lllll}0 & 0 & 0 & 0 & 0.0 \%\end{array}$

They have anti-malarial drugs and take it when necessary

$\begin{array}{lllll}0 & 0 & 0 & 0 & 0.0 \%\end{array}$

It is unnecessary to see the doctor/health worker for recovering from malaria

$\begin{array}{rrrrr}4 & 11 & 4 & 19 & 7.3 \% \\ 0 & 0 & 2 & 2 & 0.8 \% \\ 68 & 82 & 26 & 176 & 67.2 \%\end{array}$

It is too expensive to see the doctor/health worker

$\begin{array}{rrrrr}23 & 1 & 2 & 26 & 9.9 \% \\ 0 & 24 & 7 & 31 & 11.8 \%\end{array}$

It is too far to go to see the doctor/health worker

Other reasons

Don't answer

6. How can someone protect themselves against malaria?*

Sleep under treated bed net

Untreated mosquito net

Use mosquito repellent

Use mosquito insecticide spray (Shelltox)

Take preventive medication

Indoor residual spray (IRS)

Use mosquito coils

Cut grass around house

Eliminate stagnant water

Keep surroundings clean

Don't drink dirty water

Contaminated food

Use mosquito screens on windows and doors

$\begin{array}{rrrrr}5 & 7 & 1 & 13 & 5.0 \%\end{array}$

Others: specify

Don't answer

$\begin{array}{rrrrr}71 & 93 & 34 & 198 & 75.6 \% \\ 0 & 1 & 0 & 1 & 0.4 \%\end{array}$

$\begin{array}{rrrrr}1 & 2 & 1 & 4 & 1.5 \% \\ 10 & 7 & 3 & 20 & 7.6 \%\end{array}$

$\begin{array}{lllll}10 & 7 & 3 & 20 & 7.6 \%\end{array}$

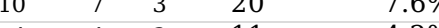

$\begin{array}{rrrrr}4 & 4 & 3 & 11 & 4.2 \% \\ 1 & 3 & 3 & 7 & 2.7 \%\end{array}$

$\begin{array}{rrrrr}1 & 3 & 3 & 7 & 2.7 \% \\ 5 & 8 & 2 & 15 & 5.7 \%\end{array}$

$\begin{array}{lllll}6 & 5 & 0 & 11 & 4.2 \%\end{array}$

$\begin{array}{lllll}7 & 9 & 5 & 21 & 8.0 \%\end{array}$

$\begin{array}{rrrrr}7 & 44 & 13 & 84 & 32.1 \%\end{array}$

$\begin{array}{lllll}1 & 1 & 1 & 3 & 1.1 \%\end{array}$

$\begin{array}{lllll}2 & 3 & 2 & 7 & 2.7 \%\end{array}$

$\begin{array}{lllll}2 & 1 & 3 & 6 & 2.3 \%\end{array}$

In water

In weed

In rubbish

\begin{tabular}{rrrrr}
11 & 10 & 3 & 24 & $9.2 \%$ \\
1 & 1 & 1 & 3 & $1.1 \%$ \\
\hline 49 & 77 & 27 & 153 & $58.4 \%$ \\
0 & 4 & 0 & 4 & $1.5 \%$ \\
25 & 20 & 9 & 54 & $20.6 \%$
\end{tabular}

Page 9/10 
I don't know

*: it is a multiple-choice question. 